\title{
A Case Report: Challenge in Treatment of a Rare Condition of Gonadal Agenesis and Bipolar Disease
}

\author{
Aytan Mammadova, Dhivya Pahwa, Wefag Ahmed, Mohd Elmugtaba Ibrahim, Nunlee-Bland Gail, \\ Anteneh Zenebe, Wolali A. Odonkor
}

Department of Endocrinology, Howard University Hospital, Washington DC, USA

Email: dr.aytan.mammadova@gmail.com,dpahwa@huhosp.org,wahmed@huhosp.org, memibrahim91@gmail.com, gnunlee-bland@Howard.edu, azenebe@Howard.edu

How to cite this paper: Mammadova, A., Pahwa, D., Ahmed, W., Ibrahim, M.E., Gail, N.-B., Zenebe, A. and Odonkor, W.A. (2021) A Case Report: Challenge in Treatment of a Rare Condition of Gonadal Agenesis and Bipolar Disease. Open Journal of Endocrine and Metabolic Diseases, 11, 181-185. https://doi.org/10.4236/ojemd.2021.1112017

Received: November 16, 2021

Accepted: December 25, 2021

Published: December 28, 2021

Copyright $\odot 2021$ by author(s) and Scientific Research Publishing Inc. This work is licensed under the Creative Commons Attribution International License (CC BY 4.0).

http://creativecommons.org/licenses/by/4.0/

\section{(c) (i) Open Access}

\begin{abstract}
Background: We report a rare case of congenital bilateral testicular agenesis who presented with a suicide attempt. We pose the question of testosterone therapy could improve his mental health. Case Report: A 36-year-old man was admitted to a psychiatric ward after the suicide attempt. An endocrinology consult is requested to address if hormone replacement therapy could improve his depression and future suicide attempts. His past medical history is significant for gonadal agenesis, testicular implants placement at age 16, bipolar type 1 diagnosed 2 years ago before the presentation. The patient received testosterone replacement treatment at age $13-15$ years. Since that time, he has not been placed on any testosterone therapy. Physical exam revealed minimal axillary and pubic hair, testicular implants with a microphallus. Laboratory values reflect hypergonadotropic hypogonadism consistent with testicular agenesis. He was suicidal and testosterone treatment was deferred. Discussion: It is a rare case of congenital testicular agenesis with bipolar disorder which was resistant to therapy. The patient had profound hypogonadism, which needed testosterone replacement therapy. However, the therapy was deferred because of an acute psychotic condition. This case also highlights that there is no strong evidence of the effect of hormonal therapy on mental health in this group.
\end{abstract}

\section{Keywords}

Congenital Anorchia, Gonadal Agenesis, Suicide Attempt, Bipolar Disease, Hypogonadism

\section{Introduction}

Congenital agonadism is also known as congenital anorchia, male gonadal age- 
nesis, testicular agenesis, vanishing testes syndrome, regressed testes syndrome [1]. The incidence is very rare and is estimated at $0.5-1$ in 20,000 alive live birth [1]. It also represents approximately $20 \%$ of males with undescended testes [2].

The diagnosis is made in the absence of palpable testis in the testicular sac and is sometimes discovered in young male children as with our patient or based on regular healthy appointments [1]. The exact etiology of his condition is not clearly explained and reported [1]. A genetic test reveals $46 \mathrm{XY}$ genotypes and a normal male appearance [2] [3].

The exact etiology of his condition is not clearly explained and reported [1] [2]. It is suggested that the syndrome is due to regression of the testis at the late stage of prenatal development [1]. There are no studies identifying testosterone treatment and mental health in this group of patients [4]. The literature reports that this disease tends to sequester within families [5]. However, some studies have shown testosterone treatment stimulates penile growth and talk about the important role of testosterone trial in the treatment of micropenis which may present during different clinical syndromes and conditions [6]. Prepubertal testosterone treatment is usually recommended for bone growth [6]. Preadolescent testosterone injection increased the penile size; however, this growth response was temporary and did not appear to be predictive of the eventual adult size of the penis [6].

Few genetic disorders are reported in the literature which present with hypogonadism and mental-psychiatric conditions and like attention deficit, autism, depression, anxiety, hyperactivity disorder, schizophrenia, bipolar, and hypogonadism [7] [8]. Testosterone has a neuroprotective and neurotrophic effect on the brain [7] [8]. It can also explain the neuropsychiatric presentation of hypogonadism and syndromes associated with hypogonadism, like Klinefelter, agonadal agenesis, and etc. [7] [8] [9].

\section{Case Report}

A 36-year-old man with a past medical history of bipolar disorder, previous suicide attempts, and testicular agenesis was admitted to a psychiatric ward after a suicide attempt by jumping into traffic. Our encounter with the patient was after an endocrine consult to address his testicular agenesis, subsequent psychiatric complication, and the questionable benefit of hormone replacement therapy to improve his depression with multiple suicide attempts. The patient revealed to us that his gonadal agenesis was diagnosed at birth and was worked up extensively. He subsequently had testicular implants placement at age 16 . The patient was seen by an endocrinologist and received testosterone hormonal replacement treatment at age 13 - 15 years and lost follow-up after.

The patient denies any family history of testicular agenesis syndrome and has a brother with normal testes and male development. He is currently taking valproate $500 \mathrm{mg}$ by mouth twice a day, quetiapine $200 \mathrm{mg}$ by mouth at bedtime. He was placed on several different bipolar and anti-psychiatric medications in the recent past. The patient is single, he reports minimal sexual history reporting 
a great deal of effort required to engage in intercourse. The patient also reports homelessness, uses cannabis, smokes cigarettes 4 - 5 packages daily since age 13 .

Physical exam revealed his height $170 \mathrm{~cm}$, weight $110 \mathrm{~kg}$, body mass index 38.1 sparse facial and body hair, noting minimal axillary and pubic hair. There was the presence of a grossly hypoplastic scrotum with testicular prosthetic, microphallus with a stretched penile length of $3 \mathrm{~cm}$. No hypospadias was present, laboratory studies i.e. $\mathrm{LH}, \mathrm{FSH}$, and testosterone values reflect hypergonadotropic hypogonadism consistent with testicular agenesis:

\begin{tabular}{ccc}
\hline Hormones & Reported level & Normal range \\
\hline Free testosterone & $0.41 \mathrm{ng} / \mathrm{dL}$ & $3.5-15.5 \mathrm{ng} / \mathrm{dL}$ \\
Total testosterone & $24 \mathrm{ng} / \mathrm{dL}$ & $286-1511 \mathrm{ng} / \mathrm{dL}$ \\
AM cortisol & $15.31 \mathrm{mcg} / \mathrm{dL}$ & $5-25 \mathrm{mcg} / \mathrm{dL}$ \\
FSH & $61.41 \mathrm{mIU} / \mathrm{mL}$ & $0.7-11.1 \mathrm{mIU} / \mathrm{mL}$ \\
LH & $23.47 \mathrm{IU} / \mathrm{L}$ & $1.4-7.7 \mathrm{IU} / \mathrm{L}$ \\
Prolactin & $13.75 \mathrm{ng} / \mathrm{ml}$ & $2.5-17 \mathrm{ng} / \mathrm{ml}$ \\
\hline
\end{tabular}

We do not have a DXA scan or X-ray to determine his bone age/maturation.

The patient was acutely suicidal and testosterone treatment is not indicated in acute psychiatric conditions. Therefore, testosterone replacement therapy was deferred. After discharge endocrine follow-up was established to begin testosterone replacement therapy.

\section{Discussion}

Gonadal agenesis is a very rare syndrome with $0.5-1$ in 20.000 alive birth [1]. Normal male karyotype and phenotype is a typical presentation of this group of patients [1] [2] [3]. There is no evidence in the literature of hormonal replacement therapy in adulthood, and evidence is lacking to show the effect of hormonal therapy on the quality of life, mental health, and hypogonadism in gonadal agenesis patients [4].

Our patient had profound hypogonadism with free testosterone level was 0.41 $\mathrm{ng} / \mathrm{dL}$ (3.5 - $15.5 \mathrm{ng} / \mathrm{dL})$, total testosterone $24 \mathrm{ng} / \mathrm{dL}$ (286 - $1511 \mathrm{ng} / \mathrm{dL})$.

Testosterone replacement therapy is the mainstay of treatment in hypogonadal patients, which applies to gonadal agenesis patients as well [9]. The evidence is not well-supported for hormonal replacement therapy in acutely mentally ill patients. Some studies have shown higher rates of homicide with testosterone replacement therapy [10]. The only reported therapy in congenital anorchia is pubertal testosterone therapy [9].

Despite increasing recognition of hormonal role in mood disorders, the underlying mechanism is not well understood [7]. Several clinical conditions with hormonal imbalance are associated with psychopathologies, in Turner syndrome, Klinefelter, polycystic ovarian syndrome, congenital adrenal hyperplasia, familial male precocious puberty, and androgen sensitivity syndrome [7] [8] [9]. 
Endogenous testosterone has a well-established association with bipolar disorder [7]. However, there is no large sample-sized study to measure and estimate the hormonal level and depression score [7]. A small sample-sized study was published measuring the salivary testosterone level and depression and did not reveal any strong relationship [7].

Some studies showed that the level of testosterone may be related to the disease process of bipolar disorder, depression and suicidal behavior [11]. Interestingly this level is not the same in males and females and differs by gender [7] [12] [13]. In males' bipolar disease is more prevalent in hypogonadal men, however, among women this disorder is more common in females with higher testosterone levels [7] [12] [13]. It is also suggested to check testosterone level before bipolar assessment and treatment [10]. However, the study could not comment on the neurobiological effect of testosterone on bipolar disease and suicidal attempts [10] [13].

A systematic review and meta-analysis of 7 double-blind placebo-controlled studies was published in 2009 , looked at if the testosterone replacement therapy has an antidepressant effect in depressed patients especially those with hypogonadism [11]. For comparison and measurement method they used Hamilton Rating Scale for Depression (HAM-D) [11].

A meta-analysis of 16 randomized studies showed the significant effect of exogenous testosterone on mood in hypogonadal men [6]. This effect is more pronounced in men aged $<60$ years. Testosterone treatment on depression was not significant in eugonadal patients. The testosterone administration route did not differ [6].

Studies have found testosterone administration has higher rates of psychiatric disorders in suicide and homicide offenders than in the general population [10] [13].

However, further studies are needed to determine optimal therapeutic regimens and follow-up schedules to determine the difference in mental status [10] [13].

We present this case as a rare condition of gonadal agenesis to add to the current literature and to also highlight the lack of literature with regards to associated psychiatric manifestations of gonadal agenesis and the effect of testosterone treatment in adulthood.

\section{Conclusion}

We present this case as a rare condition of gonadal agenesis to add to the current literature and to also highlight the lack of literature and insufficient information of testosterone replacement treatment with regards to associated psychiatric manifestations of gonadal agenesis.

\section{Conflicts of Interest}

The authors declare no conflicts of interest regarding the publication of this paper. 


\section{References}

[1] Rousso, I., Iliopoulos, D., Athanasiadou, F., Zavopoulou, L., Vassiliou, G. and Voyiatzis, N. (2006) Congenital Bilateral Anorchia: Hormonal, Molecular and Imaging Study of a Case. Genetics and Molecular Research, 5, 638-642.

[2] Jespersen, K., Ljubicic, M.L., Johannsen, T.H., Christiansen, P., Skakkebaek, N.E. and Juul, A. (2020) Distinguishing between Hidden Testes and Anorchia: The Role of Endocrine Evaluation in Infancy and Childhood. European Journal of Endocrinology, 183, 107-117. https://doi.org/10.1530/EJE-20-0041

[3] Parigi, G.B., Bardoni, B., Avoltini, V., Caputo, M.A. and Bragheri, R. (1999) Is Bilateral Congenital Anorchia Genetically Determined? European Journal of Pediatric Surgery, 9, 312-315. https://doi.org/10.1055/s-2008-1072271

[4] Bernasconi, S., Ghizzoni, L., Panza, C., Volta, C. and Caselli, G. (1992) Congenital Anorchia: Natural History and Treatment. Hormone Research in Paediatrics, 37, 50-54. https://doi.org/10.1159/000182401

[5] Philibert, P., Zenaty, D., Lin, L., Soskin, S., Audran, F., Léger, J., et al. (2007) Mutational Analysis of Steroidogenic Factor 1 (NR5al) in 24 Boys with Bilateral Anorchia: A French Collaborative Study. Human Reproduction, 22, 3255-3261. https://doi.org/10.1093/humrep/dem278

[6] Hatipoglu, N. and Kurtoglu, S. (2013) Micropenis: Etiology, Diagnosis and Treatment Approaches. Journal of Clinical Research in Pediatric Endocrinology, 5, 217 223. https://doi.org/10.4274/Jcrpe.1135

[7] Mousavizadegan, S. and Maroufi, M. (2018) Comparison of Salivary Testosterone Levels in Different Phases of Bipolar I Disorder and Control Group. Journal of Research in Medical Sciences, 23, Article No. 31.

[8] Giagulli, V.A., Campone, B., Castellana, M., Salzano, C., Fisher, A.D., de Angelis, C., et al. (2019) Neuropsychiatric Aspects in Men with Klinefelter Syndrome. Endocrine, Metabolic \& Immune Disorders-Drug Targets, 19, 109-111. https://doi.org/10.2174/1871530318666180703160250

[9] Kanakis, G.A. and Nieschlag, E. (2018) Klinefelter Syndrome: More than Hypogonadism. Metabolism, 86, 135-144. https://doi.org/10.1016/j.metabol.2017.09.017

[10] Sher, L. and Landers, S. (2014) Bipolar Disorder, Testosterone Administration, and Homicide: A Case Report. International Journal of Psychiatry in Clinical Practice, 18, 215-216. https://doi.org/10.3109/13651501.2014.894075

[11] Zarrouf, F.A., Artz, S., Griffith, J., Sirbu, C. and Kommor, M. (2009) Testosterone and Depression: Systematic Review and Meta-Analysis. Journal of Psychiatric Practice, 15, 289-305. https://doi.org/10.1097/01.pra.0000358315.88931.fC

[12] Wooderson, S.C., Gallagher, P., Watson, S. and Young, A.H. (2015) An Exploration of Testosterone Levels in Patients with Bipolar Disorder. BJPsych Open, 1, 136-138. https://doi.org/10.1192/bjpo.bp.115.001008

[13] Sher, L., Grunebaum, M.F., Sullivan, G.M., Burke, A.K., Cooper, T.B., Mann, J.J., et al. (2012) Testosterone Levels in Suicide Attempters with Bipolar Disorder. Journal of Psychiatric Research, 46, 1267-1271. https://doi.org/10.1016/j.jpsychires.2012.06.016 